\title{
Biochemical aspirin resistance in acute stroke patients and its association with clinical factors: a prospective pilot study
}

\author{
Michał Morton, Katarzyna Kubiak-Balcerewicz, Anna Sarnowska, Urszula Fiszer \\ Department of Neurology and Epileptology, Centre of Postgraduate Medical Education, Orłowski Hospital, Warsaw, Poland
}

\begin{abstract}
Introduction: Aspirin is still widely used in treatment and prevention of cardiovascular diseases. To predict which patients cannot benefit from aspirin due to aspirin resistance remains a great clinical challenge.

Material and methods: Fifty one acute stroke/transient ischemic attack (TIA) patients (ASG) with a history of regular aspirin intake for the previous 7 days or more were included to the study within 24 hours of symptoms onset. Twenty nine patients admitted to our department for other reasons were the controls (CG). Each patient underwent routine blood tests (white blood cells, platelets, total cholesterol, C-reactive protein) and additional blood test: glycated haemoglobin (HbA1c), insulin, and N-terminal prohormone of brain natriuretic peptide (NT-proBNP). Biochemical aspirin resistance was measured using the VerifyNow Aspirin platelet function analyzer.

Results: There were 9 aspirin resistance patients in ASG $(17.5 \%)$ and 3 in CG $(10.3 \%)(p=0.38)$. There were no differences in either age or gender between those groups. Twelve aspirin-resistant patients differed from aspirin nonresistant patients in age, NT-proBNP and total cholesterol levels (univariate model, $p=0.004,0.04,0.02$, respectively). In a multivariate model patients aged 76 years and more would likely to be aspirin resistant with odds ratio $=9$ (95\% confidence interval: 1-78).

Conclusions: Patients aged 76 and more can be more likely aspirin resistant than younger patients. We believe that especially in the elderly with congestive heart failure there is a strong need for further investigations in this field, including searching for alternative antiplatelet therapies.
\end{abstract}

Key words: aspirin resistance, stroke, age, NT-ProBNP.

\section{Introduction}

Aspirin still plays a crucial role in secondary stroke prevention reducing the risk of recurrent stroke by around 22\% [2] and may be even as effective as intravenous thrombolysis in managing of acute ischemic stroke with minor non-disabling neurologic deficits [14]. The term "aspirin resistance" widely used in the literature is difficult to define and encompasses clinical, pathophysiologic and biochemical resistance. Some authors emphasize that despite aspirin resistance is common, poor compliance may account for nearly half of cases of apparent aspirin "failure" [6]. Other findings highlight that laboratory aspirin resistance due to insufficient platelet inhibition is relatively uncommon, whereas pathophysiologic resistance, signifying the presence of aetiologies that cannot be effectively treated

\section{Communicating author}

Katarzyna Kubiak-Balcerewicz, Department of Neurology and Epileptology, Centre of Postgraduate Medical Education,

Orłowski Hospital, Warsaw, Poland, e-mail: katarzyna.izabela@gmail.com 
with aspirin, mainly contribute to clinical aspirin resistance in ischemic stroke $[1,26]$. The results of many published studies may seem conflicting and the mechanisms are not fully understood, but multifactorial aetiology of aspirin resistance is considered to be undisputed. Which patients cannot benefit from aspirin - this question still remains the greatest clinical challenge in this field. Biochemical aspirin resistance in acute ischemic stroke may be associated with short- and long-term mortality [18], increased stroke severity and infarct size [17,29]. It may also predict an early neurological deterioration [4] and unfavourable functional outcome in acute ischemic stroke patients [24]. As a broadly defined aspirin resistance phenomenon may possibly affect treatment of millions worldwide we set up our prospective pilot study. The goal of our study was to define frequency of biochemical aspirin resistance in acute stroke patients and to find out which other factors, especially of those measured in routine practice may be associated with this phenomenon. We also hoped to set up proper methods for this kind of the study as we wish to perform a study covering a larger group of patients in the future. We believe this could help in distinguishing patients who are in need of alternative antiaggregant therapies.

\section{Material and methods}

The study protocol was approved by the local Bioethics Committee at the Centre of Postgraduate Medical Education in Warsaw. Acute stroke patients and transient ischemic attack (TIA) patients with a history of regular aspirin intake for the previous 7 days or more, in dosage of 75-300 mg per day, consecutively admitted to our department were included to the study within 24 hours of symptoms onset. Although an antiaggregant effect of aspirin develops rapidly after the drug had been introduced, we set up 7 days' regular aspirin intake cut-off as acute stroke patients usually stay around 7 days in the acute stroke department and measuring aspirin biochemical resistance after 7 days of proven intake in the acute stroke department, could be an interesting study for the future. Patients admitted to our department for reasons other than acute neurological symptoms who declared regular aspirin intake for the previous 7 days or more were included to the control group. Patients on dual antiplatelet therapy were not enrolled to the study. Each patient under- went computed tomography (CT) scan of the brain, routine blood tests (including white blood cells, platelets, total cholesterol, C-reactive protein - CRP) and additional blood test: glycated haemoglobin $\left(\mathrm{HbA}_{1 \mathrm{c}}\right)$, insulin, the $\mathrm{N}$-terminal prohormone of brain natriuretic peptide (NT-proBNP). Biochemical aspirin resistance was measured using the VerifyNow Aspirin platelet function analyzer. Two samples of $2 \mathrm{ml}$ blood were taken using the vacuum system. The first sample was disposed in order to exclude artificial mechanical platelet damage, the second blood sample was examined. Arachidonic acid-induced platelet aggregation had been quantitated in Aspirin Reaction Units (ARU). ARU $\geq 550$ indicated aspirin resistance (according to the manufacturer's insert).

\section{Results}

Eighty patients were included to the study, fifty one patients to the acute stroke/TIA group (ASG) and 29 patients to the control group (CG). There was no statistically significant difference either in age between those groups (Student's $t$-test, $p=0.08$ ) or in gender $\left(\chi^{2}\right.$ test, $\left.p=0.91\right)$. There were nine aspirin resistance patients in ASG (17.5\%) and three in CG $(10.3 \%)$. There was no statistically significant difference in the prevalence of aspirin resistance between those groups (Student's $t$-test, $p=0.38$ ). In the whole study group (80 patients), 12 patients appeared to be aspirin resistant (AR), whereas 68 patients - aspirin non-resistant (ANR).

Characteristics of aspirin-resistant vs. aspirin non-resistant patients has been shown in Table I.

There was a statistically significant difference in age between AR and ANR group (Student's t-test, $p=0.004)$, but no statistically significant difference in gender ( $\chi^{2}$ test, $p=0.66$ ). The AR group also differed from the ANR group in total cholesterol levels (Mann-Whitney test, $p=0.02$ ) and NT-proBNP levels (Mann-Whitney test, $p=0.04$ ). No statistically significant differences were found in CRP levels (Mann-Whitney test, $p=0.98$ ), white blood cells levels (Mann-Whitney test, $p=0.56$ ), insulin levels (Mann-Whitney test, $p=0.28$ ), $\mathrm{HbA}_{1 \mathrm{c}} \%$ (Mann-Whitney test, $p=0.66$ ) and platelets levels (Mann-Whitney test, $p=0.56$ ).

Three variables which differed the AR group from the ANR group (age, total cholesterol level, NT-proBNP level) were included in the logistic regres- 
Table I. Characteristics of aspirin-resistant vs. aspirin non-resistant patients

\begin{tabular}{|c|c|c|c|}
\hline Parameter & AR & ANR & $p$-value \\
\hline Number of patients & 12 & 68 & \\
\hline Mean ARU (units) & $591.5 \pm 44.0$ & $453.2 \pm 44.3$ & 0.0001 \\
\hline Median ARU (units) & 582 & 537.5 & \\
\hline Mean age (years) & $80.1 \pm 7.0$ & $72.2 \pm 10.3$ & 0.004 \\
\hline Median age (years) & 82 & 75.5 & \\
\hline Number of women & 7 & 35 & 0.66 \\
\hline Mean total cholesterol (mg/dl) & $147.2 \pm 26.9$ & $171 \pm 41.5$ & 0.02 \\
\hline Median total cholesterol (mg/dl) & 133 & 167 & \\
\hline Mean NT-proBNP (pg/ml) & $1201 \pm 1181.3$ & $834.7 \pm 1371.4$ & 0.04 \\
\hline Median NT-proBNP (pg/ml) & 704 & 319 & \\
\hline Mean CRP (mg/l) & $10.9 \pm 18$ & $12.4 \pm 29.5$ & 0.98 \\
\hline Median CRP $(\mathrm{mg} / \mathrm{l})$ & 7 & 7 & \\
\hline Mean insulin $(\mu \mathrm{IU} / \mathrm{ml})$ & $12.9 \pm 12.2$ & $20.4 \pm 24.0$ & 0.28 \\
\hline Median insulin $(\mu \mathrm{IU} / \mathrm{ml})$ & 9.4 & 11.7 & \\
\hline Mean $\mathrm{HbA}_{1 \mathrm{c}} \%$ & $6.1 \pm 0.9$ & $6.3 \pm 1.0$ & 0.66 \\
\hline Median $\mathrm{HbA}_{1 c} \%$ & 5.9 & 6 & \\
\hline Mean platelets $\left(\times 10^{9} / \mathrm{l}\right)$ & $214.0 \pm 45.2$ & $225.7 \pm 65.9$ & 0.56 \\
\hline Median platelets $\left(\times 10^{9} / \mathrm{l}\right)$ & 219.5 & 213.5 & \\
\hline
\end{tabular}

$A R$ - aspirin-resistant patients, $A N R$ - aspirin non-resistant patients, $A R U$ - aspirin resistance units, NT-proBNP - N-terminal prohormone of brain natriuretic peptide, CRP - C-reactive protein, WBC - white blood cells, $H b A_{1 c}$ - glycated haemoglobin

sion model (stepwise method, forward Wald). Age appeared to be the only significant variable in this model - patients aged 76 years and more would likely to be aspirin resistant with odds ratio (OR) $=9.95 \%$ confidence interval $(\mathrm{Cl})$ for OR range 1-78.

\section{Discussion}

The prevalence of aspirin resistance varies from study to study, ranging from about 5\% to $60 \%$ $[9,15,28]$. A meta-analysis of 52 full-text studies covering 8364 ischemic stroke/TIA patients on aspirin or clopidogrel revealed that the prevalence of high ontreatment of platelet reactivity to aspirin is $23 \%$ [8]. In our study the prevalence of aspirin resistance among acute stroke patients was $17.3 \%$. However, platelet reactivity to aspirin can change over time in a significant proportion of patients, therefore single platelet activity measurements may not be reliable and serial ARU measurement may identify acute stroke patients who are at higher risk of vascular events [2]. Moreover, aspirin biochemical resistance may decrease with a higher aspirin dose [10,25]. About 20\% differences in aspirin biochemical resistance occurrence might be observed when measuring in either hospital or ambulatory conditions [20]. Sabra et al. also observed that many patients receiving low-dose aspirin met the criteria of aspirin resistance but the prevalence was much lower at 3-5 days of inpatient aspirin treatment [20]. The findings of this study [20] as well as of the study from El-Mitwalli et al. [7] also highlight the aspirin "pseudo resistance" phenomenon due to medication noncompliance. A variety of platelet activation tests and a lack of its standardization is a separate issue.

In our study there was no statistically significant difference in gender between aspirin responders and aspirin non-responders, whereas several studies showed less effective inhibition of platelet aggregation by aspirin in women, and this was believed to be caused by the influence of female sex hormones $[23,30]$. However there are also data suggesting aspirin resistance may be more frequent in males [7]. Older age (76 years and more) was the only variable statistically significant factor in the logistic regression model in our study. These results might be supported by results of some other studies. In the study of Suanprasert et al. [23], older patients (64.8 years) were likely to be aspirin resistant than younger patients (61.3 years) with $p=0.049$. Univariate analysis by Seok et al. [21] also revealed (using VerifyNow Aspirin Assay) that older age is related to aspirin resistance $(67.6 \pm 9.3$ years vs. $58.3 \pm 11.5$ years with OR 1.07 per 
1-year increase, 95\% Cl: 0.97-1.17, $p=0.01$ ). However, in the study covering 21 stroke patients identified as primary aspirin non-responders, there were no significant differences between aspirin responders and aspirin non-responders concerning age, gender, risk factors and stroke characteristics [3]. No association between platelet aggregation and age, gender, dose of ASA has been also found in the study on type 2 diabetes mellitus patients [16]. The history of current smoking $(p=0.03)$, the mean total cholesterol $(p=0.02), \mathrm{LDL}$ concentration $(p=0.005)$, white blood cells $(p=0.03)$, haematocrit $(p=0.01)$ and platelet level $(p=0.05)$ were significantly higher in aspirin non-responders in this study [16]. Aspirin non-responders were treated shorter with aspirin than responders $(p=0.01)[16]$. Those results are in conflict with the results of our study suggesting that lower total cholesterol levels may be associated with aspirin resistance, and that white blood cell and platelet levels are not associated with aspirin resistance. However, those differences might be caused by the fact that 9 of our 12 aspirin-resistant patients had acute neurological symptoms, and many of them were not diabetic. Worse control of diabetes and higher baseline levels of inflammation (mean CRP $26.4 \pm 56.0$ vs. $9.3 \pm 21.0, p<0.01$ ) were main determinants for the antiplatelet drug resistance [5]. Our study revealed that CRP level does not differ between aspirin resistant and aspirin non-resistant patients, which could be supported by the results of some other studies [11,12]. Habizal et al. [11] also revealed that $\mathrm{HbA}_{1 c}$ levels do not differ between aspirin resistant and aspirin non-resistant patients, and so did we. Hypertriglyceridemia may also affect platelet response to aspirin [13,22], as well as high total cholesterol/HDL ratio [19]. High levels of LDL and diabetes have been found to be independent risk factors for aspirin resistance and aspirin semiresistance in Chinese stroke patients [27]. We found NT-proBNP to be a significant variable in the univariate model. In the study of Fong et al. [9], patients with congestive heart failure and those with higher haemoglobin A1c values had a significantly greater likelihood of having a biochemical nonresponse to aspirin therapy.

\section{Conclusions}

The results of our pilot study suggest that patients aged 76 and more have greater possibili- ty to be aspirin resistant than younger patients. We believe that especially among elderly patients with congestive heart failure, there is a strong need of further investigations in this field, including searching for alternative antiplatelet therapies.

\section{Acknowledgements}

This study was supported by grant no. 501-1-1416-16 from the Centre of Postgraduate Medical Education, Warsaw, Poland.

\section{Disclosure}

The authors report no conflict of interest.

\section{References}

1. Agayeva N, Gungor L, Topcuoglu MA, Arsava EM. Pathophysiologic, rather than laboratory-defined resistance drives aspirin failure in ischemic stroke. J Stroke Cerebrovasc Dis 2015; 24: 745-750.

2. Baigent C, Blackwell L, Collins R, Emberson J, Godwin J, Peto R, Buring J, Hennekens C, Kearney P, Meade T, Patrono C, Roncaglioni MC, Zanchetti A. Aspirin in the primary and secondary prevention of vascular disease: collaborative meta-analysis of individual participant data from randomised trials. Lancet 2009; 373: 1849-1860.

3. BerrouschotJ, Schwetlick B, von Twickel G, Fischer C, Uhlemann H, Siegemund T, Siegemund A, Roessler A. Aspirin resistance in secondary stroke prevention. Acta Neurol Scand 2006; 113: 31-35.

4. Bugnicourt JM, Roussel B, Garcia PY, Canaple S, Lamy C, Godefroy O. Aspirin non-responder status and early neurological deterioration: a prospective study. Clin Neurol Neurosurg 2011; 113: 196-201.

5. Coignion C, Poli M, Sagnier S, Freyburger G, Renou P, Debruxelles S, Rouanet F, Sibon I. Interest of Antiplatelet Drug Testing after an Acute Ischemic Stroke. Eur Neurol 2015; 74: 135-139.

6. Dawson J, Quinn T, Rafferty M, Higgins P, Ray G, Lees KR, Walters MR. Aspirin resistance and compliance with therapy. Cardiovasc Ther 2011; 29: 301-307.

7. El-Mitwalli A, Azzam H, Abu-Hegazy M, Gomaa M, Wasel Y. Clinical and biochemical aspirin resistance in patients with recurrent cerebral ischemia. Clin Neurol Neurosurg 2013; 115: 944-947.

8. Fiolaki A, Katsanos AH, Kyritsis AP, Papadaki S, Kosmidou M, Moschonas IC, Tselepis AD, Giannopoulos S. High on treatment platelet reactivity to aspirin and clopidogrel in ischemic stroke: A systematic review and meta-analysis. J Neurol Sci 2017; 376: 112-116.

9. Fong J, Cheng-Ching E, Hussain MS, Katzan I, Gupta R. Predictors of biochemical aspirin and clopidogrel resistance in patients with ischemic stroke. J Stroke Cerebrovasc Dis 2011; 20: 227-330. 
10. Gengo F, Westphal ES, Rainka MM, Janda M, Robson MJ, Hourihane JM, Bates V. Platelet response to increased aspirin dose in patients with persistent platelet aggregation while treated with aspirin $81 \mathrm{mg}$. I Clin Pharmacol 2016; 56: 414-421.

11. Habizal NH, Abdul Halim S, Bhaskar S, Wan Bebakar WM, Abdullah JM. Prevalence of Aspirin Resistance in Diabetic Patients and its Associated Factors. Malays I Med Sci 2015; 22: 50-57.

12. Halawani SH, Williams DJ, Adefurin A, Webster J, Greaves M, Ford I. Aspirin Failure in Patients Presenting With Acute Cerebrovascular Ischaemia. Thromb Haemost 2011; 106: 240-247.

13. Karepov V, Tolpina G, Kuliczkowski W, Serebruany V. Plasma triglycerides as predictors of platelet responsiveness to aspirin in patients after first ischemic stroke. Cerebrovasc Dis 2008; 26: $272-276$

14. Khatri P, Kleindorfer DO, Devlin T, Sawyer RN Jr, Starr M, Mejilla J, Broderick J, Chatterjee A, Jauch EC, Levine SR, Romano JG, Saver JL, Vagal A, Purdon B., Devenport J, Pavlov A, Yeatts SD. Effect of alteplase vs aspirin on functional outcome for patients with acute ischemic stroke and minor nondisabling neurologic deficits. The PRISMS Randomized Clinical Trial. JAMA 2018; 320: 156-166.

15. Kim KE, Woo KS, Goh RY, Quan ML, Cha KS, Kim MH, Han JY. Comparison of laboratory detection methods of aspirin resistance in coronary artery disease patients. Int I Lab Hematol 2010; 32: 50-55.

16. Łabuz-Roszak B, Pierzchała K, Tyrpień K. Resistance to acetylsalicylic acid in patients with type 2 diabetes mellitus is associated with lipid disorders and history of current smoking. J Endocrinol Invest 2014; 37: 331-338.

17. Oh MS, Yu KH, Lee JH, Jung S, Kim C, Jang MU, Lee J, Lee BC. Aspirin resistance is associated with increased stroke severity and infarct volume. Neurology 2016; 86: 1808-1817.

18. Ozben S, Ozben B, Tanrikulu AM, Ozer F, Ozben T. Aspirin resis tance in patients with acute ischemic stroke. J Neurol 2011; 258 : 1979-1986.

19. Postuła M, Tarchalska-Kryńska B, Filipiak KJ, Kosior D, Serafin A, Huczek Z, Opolski G. Factors responsible for "aspirin resis tance" - can we identify them? Kardiol Pol 2010; 68: 403-411.

20. Sabra A, Stanford S, Storton S, Lawrence M, D'Silva L, Morris RH, Evans V, Wani M, Potter JF, Evans PA. Assessment of platelet function in patients with stroke using multiple electrode platelet aggregometry: a prospective observational study. BMC Neurol 2016; 16: 254

21. Seok J, Joo IS, Yoon JH, Choi YJ, Lee PH, Huh K, Bang OY. Can aspirin resistance be clinically predicted in stroke patients? Clin Neurol Neurosurg 2008; 110: 110-116.

22. Staszewski J, Piusińska-Macoch R, Skrobowska E, Brodacki B, Macek K, Stępień A. Aspirin resistance: risk factors and prognostic significance in patients with cerebral small vessel disease. Ann Clin Lab Sci 2018; 48: 45-54.

23. Suanprasert N, Yadee T, Mahasirimongkol S, Jongjaroenprasert W, Tantirithisak T. Aspirin non-responder in Thai ischemic stroke patients. J Med Assoc Thai 2013; 96: 523-530.

24. Wang CW, Su LL, Hua QJ, He Y, Fan YN, Xi TT, Yuan B, Liu YX, Ji SB. Aspirin resistance predicts unfavorable functional outcome in acute ischemic stroke patients. Brain Res Bull 2018; 142: 176-182.
25. Westphal ES, Rainka M, Amsler M, Aladeen T, Wisniewski C, Bates V, Gengo FM. Prospective determination of aspirin sensitivity in patients resistant to low dose aspirin: a proof of concept study. J Clin Pharmacol 2018; 58: 1157-1163.

26. Wiśniewski A, Filipska K, Sikora J, Ślusarz R, Kozera G. The prognostic value of high platelet reactivity in ischemic stroke depends on the etiology: a pilot study. J Clin Med 2020; 9: 859.

27. Xingyang Yi, Qiang Z, Lin J, Chi L. Aspirin resistance in chinese stroke patients increased the rate of recurrent stroke and other vascular events. Int I Stroke 2013; 8: 535-539.

28. Yi X, Zhou Q, Lin J, Chi L, Han Z. Platelet response to aspirin in Chinese stroke patients is independent of genetic polymorphisms of COX-1 C50T and COX-2 G765C. J Atheroscler Thromb 2013; 20: 65-72.

29. Zheng AS, Churilov L, Colley RE, Goh C, Davis SM, Yan. Association of aspirin resistance with increased stroke severity and infarct size. JAMA Neurol 2013; 70: 208-213.

30. Zuern CS, Lindemann S, Gawaz M. Platelet function and response to aspirin: gender-specific features and implications for female thrombotic risk and management. Semin Thromb Hemost 2009; 35: 295-306. 